\title{
ATRIAL FIBRILLATION AFTER MINIMALLY INVASIVE CORONARY ARTERY BYPASS GRAFTING: A RETROSPECTIVE, MATCHED STUDY
}

William E. Cohn, MD

Cheryl A. Sirois, RN

Robert G. Johnson, MD
Background: Atrial fibrillation after cardiac operations is a source of morbidity and resource consumption. Various factors common to cardiac operations have been cited as causal. Comparison of the incidences of atrial fibrillation after conventional cardiac operations and minimally invasive cardiac operations may provide some insight into the mechanisms of this complication. Methods: All patients undergoing minimally invasive direct coronary artery bypass grafting from January 26, 1996, through September 17, 1997, were evaluated for the occurrence of inhospital postoperative atrial fibrillation. Data from these 55 patients were compared with data from a control cohort of patients undergoing conventional, solitary coronary artery bypass grafting. Each patient undergoing minimally invasive direct coronary artery bypass grafting was matched by age ( \pm 3 years) and date of operation ( \pm 7 days) with a patient undergoing conventional coronary artery bypass grafting. Results: During the period since the advent of minimally invasive direct coronary artery bypass grafting at our institution, the incidence of postoperative atrial fibrillation has been slightly lower among the patients undergoing this form of coronary artery bypass grafting (26\%) than among the total population of patients undergoing conventional coronary artery bypass grafting (34\%). Comparison of the age-matched groups, however, showed the incidence to be slightly but not significantly greater in the minimally invasive direct coronary artery bypass grafting cohort $(13 / 55,24 \%)$ than in the conventional coronary artery bypass grafting cohort $(11 / 55,20 \% ; P=.6)$. The minimally invasive direct coronary artery bypass grafting group was less likely to be discharged with antiarrhythmic therapy than was the conventional coronary artery bypass grafting group (6 versus $10 ; P=.006)$. Conclusions: According to these data, mechanisms traditionally implicated in atrial fibrillation after coronary artery bypass grafting, such as the use of cardiopulmonary bypass, mechanical manipulation of the atrium, and atrial ischemia, are not causal but may be related to the duration of the arrhythmic complication. Strategies directed toward management and reduction of the incidence of postoperative atrial fibrillation should be focused accordingly. (J Thorac Cardiovasc Surg 1999;117:298-301)
A trial fibrillation (AF) is a common complication after coronary artery bypass grafting (CABG). As such it has received much attention, because its occurrence often increases treatment resource requirements and lengthens hospital stay and it may be associated

From the Division of Cardiothoracic Surgery, Department of Surgery, Beth Israel Deaconess Medical Center and Harvard Medical School, Boston.

Received for publication March 23, 1998; revisions requested May 12, 1998; revisions received July 1, 1998; accepted for publication Sept 21, 1998 with other complications, such as hypotension or emboli. The etiology of this arrhythmia after cardiac operations is not known with certainty, but it has been related to instrumentation required for cardiopulmonary bypass, inclusive of atrial cannulation, and to the

Address for reprints: Robert G. Johnson, MD, 330 Brookline Ave, Beth Israel Deaconess Medical Center, Boston, MA 02215.

Copyright (C) 1999 by Mosby, Inc.

$0022-5223 / 99 \$ 8.00+0 \quad \mathbf{1 2 / 1 / 9 4 6 3 6}$ 
myocardial ischemia and preservation required during these procedures.

Minimally invasive direct CABG does not require atrial cannulation, cardiopulmonary bypass, or cardioplegic preservation. In this article we report the incidence of AF among patients undergoing minimally invasive direct $\mathrm{CABG}$ and compare it with the incidence among patients undergoing conventional CABG at the same institution. Our annual incidence of postoperative AF among patients undergoing solitary CABG (those undergoing no associated procedures) since 1985 has ranged from nearly $25 \%$ to $35 \%$. Our postoperative $\mathrm{AF}$ incidence among our initial patients undergoing minimally invasive direct CABG was at the lower end of this range $(24 \%, 13 / 55)$. From 1985 through 1996 our mean overall AF incidence for patients undergoing solitary CABG was $34.4 \%$, but we and others have seen a direct relationship between age and postoperative AF. During those 10 years our postoperative AF incidences by decade of age among patients undergoing solitary CABG were $0 \%, 9 \%, 18 \%$, $30 \%, 47 \%, 53 \%$, and $100 \%$, from the fourth through the 10th decades of life, respectively. To control for age as a factor affecting the incidence of postoperative AF, we sought to determine whether the incidence of postoperative AF would differ significantly between patients undergoing minimally invasive direct $\mathrm{CABG}$ and those undergoing conventional $\mathrm{CABG}$ if agematched cohorts were examined.

\section{Methods}

From January 26, 1996, through September 17, 1997, 55 patients underwent minimally invasive direct $\mathrm{CABG}$ at our institution. The minimally invasive direct $\mathrm{CABG}$ procedures consisted of grafting the left internal thoracic artery to the left anterior descending coronary artery either directly (32 patients) or by interposing an arterial conduit (23 patients). Our technique has been described previously., ${ }^{1,2}$ Briefly, it includes a single anterior thoracotomy, pericardiotomy, and left anterior descending coronary artery immobilization. These patients were not subjected to cardiopulmonary bypass, systemic hypothermia, or global cardiac ischemia with cardioplegia.

During that same period 672 patients underwent conventional, solitary (no associated procedures such as valve repairs or replacements) CABG with arterial and venous conduits to achieve revascularization during a period of hypothermic $\left(28^{\circ} \mathrm{C}-30^{\circ} \mathrm{C}\right)$ cardiopulmonary bypass with aortic crossclamping and cold blood (5:1) and hyperkalemic crystalloid solutions. $\beta$-Blockers were routinely employed as prophylaxis against postoperative $\mathrm{AF}$ in both cohorts reported on in this series.

By means of our patient registry, all the cases of patients undergoing either minimally invasive direct $\mathrm{CABG}$ or con- ventional $\mathrm{CABG}$ during the study period were reviewed for the occurrence of postoperative AF. Any noted episode of AF after operation, regardless of its duration or treatment, constituted postoperative AF. In the surgical intensive care unit continuous, automated, hard-wired monitoring was employed. After discharge all patients were continuously monitored by telemetry for at least 48 hours, and that period was extended for any patients with dysrhythmias. Telemetry was reinstituted for all patients who, after discontinuation, were noted to have tachycardia. Rate alarms detected and recorded rhythms with rates greater than 100 or less than 60 beats/min.

Patients treated before the operation for $\mathrm{AF}$ ( 4 in the minimally invasive direct $\mathrm{CABG}$ group and 82 in the conventional CABG group) were excluded from this review. After this initial review, to correct for the difference in mean age between the patients undergoing conventional CABG $(66 \pm$ 10.7 years) and the patients undergoing minimally invasive direct $\mathrm{CABG}$, each patient undergoing minimally invasive direct $\mathrm{CABG}$ was matched with a patient undergoing conventional $\mathrm{CABG}$, with age ( \pm 3 years) and date of operation ( \pm 7 days) as the sole criteria for this matching. No patient in the minimally invasive direct $\mathrm{CABG}$ group died while in the hospital, but there were 17 postoperative (in-hospital or within 30 days) deaths among the conventional CABG group. These patients were excluded from the matching process. The conventional CABG matching was done by one of us (C.S.), blinded to the patient's name or occurrence of postoperative $\mathrm{AF}$, from the entire pool of eligible patients, first searching by age and then by nearest operative date. Fourteen of the 55 patients undergoing minimally invasive direct $C A B G$ had more than single left anterior descending coronary artery disease and were treated as part of a "culprit" strategy for patients thought to be at high risk for conventional CABG, and 33 of 55 patients had more than single-vessel disease according to preoperative angiography.

The data reviewed for all patients included age, sex, unstable angina at the time of operative admission, history of previous myocardial infarction, congestive heart failure, smoking history, preoperative left ventricular ejection fraction, number of distal grafts, postoperative weight gain, postoperative complications, and length of hospital stay. Mean postoperative weight gain was defined as the difference between the preoperative weight and the weight on the first postoperative morning. Perioperative myocardial infarctions were defined as the development of new $\mathrm{Q}$ waves not visible on a preoperative electrocardiogram. Heart failure was defined as a cardiac index less than 2.0 or inotropic support 6 hours after the operation. Ventilatory failure was defined by the requirement of mechanical ventilation for longer than 48 hours. Inotropes were generally used in patients with an index less than $2.0 \mathrm{~L} / \mathrm{min} / \mathrm{m}^{2}$ with right or left filling pressures greater than $18 \mathrm{~mm} \mathrm{Hg}$.

Continuous data were analyzed by comparison of the means with the Student $t$ test. Median comparisons were made with the Wilcoxon signed rank test. Categoric data were compared with $\chi^{2}$ analysis. 
Table I. Preoperative and operative data

\begin{tabular}{llll}
\hline & $\begin{array}{c}M I D C A B \\
(n=55)\end{array}$ & $\begin{array}{c}C C A B \\
(n=55)\end{array}$ & $\mathrm{P}$ \\
\hline $\begin{array}{l}\text { Preoperative characteristics } \\
\text { Mean age (y) }\end{array}$ & $62 \pm 13.4$ & $62 \pm 13.7$ & .9 \\
Female (No.) & 18 & 12 & .19 \\
Unstable angina (No.) & 49 & 48 & $\mathrm{NC}$ \\
Previous MI (No.) & 13 & 13 & $\mathrm{NC}$ \\
Hx of CHF (No.) & 1 & 1 & $\mathrm{NC}$ \\
Hx of DM (No.) & 9 & 8 & $\mathrm{NC}$ \\
Mean LVEF (\%) & $51 \pm 10.7$ & $55 \pm 22.9$ & .09 \\
Ever smoked & 24 & 34 & $\mathrm{NC}$ \\
Operative data & & & \\
Mean No. of distal & $1.1 \pm 0.48$ & $3.6 \pm 1.1$ & .001 \\
$\quad$ anastomoses & & & \\
Mean CPB time (min) & $0 \pm 0$ & $111.7 \pm 43.9$ & $\mathrm{NC}$ \\
Mean crossclamp time (min) & $0 \pm 0$ & $82 \pm 29.8$ & $\mathrm{NC}$ \\
\hline
\end{tabular}

Data are mean \pm standard deviation or number of patients. MIDCAB, Minimally invasive direct CABG; $C C A B$, conventional CABG; $N C$, not calculated (no statistical comparison performed); $M I$, myocardial infarction; $H x$, history; $C H F$, congestive heart failure; $D M$, diabetes mellitus; $L V E F$, left ventricular ejection fraction; $C P B$, cardiopulmonary bypass.

\section{Results}

A comparison of preoperative and operative characteristics between the matched conventional CABG and minimally invasive direct $\mathrm{CABG}$ populations is shown in Table I. Appropriate to the age matching, there was no difference in mean age between the groups. Obviously, the patients undergoing conventional $\mathrm{CABG}$ had a significantly greater mean number of distal anastomoses and the minimally invasive direct $\mathrm{CABG}$ group had no cardiopulmonary bypass or crossclamp times. The overall time in the operating room ("roll in" until "roll out") did not differ significantly between the groups $(5.3 \pm 1.1$ hours for minimally invasive direct CABG versus $5.7 \pm 4.3$ hours for conventional CABG, $P=.07)$. The number of patients who required transfusion in the operating room was 7 in the minimally invasive direct $\mathrm{CABG}$ group and 12 in the conventional CABG group $(P=.3)$, and the mean numbers of units given to those patients were also not statistically different (1.86 units and 1.83 units, respectively).

In Table II the postoperative data are shown. There was no statistically significant difference in the incidence of AF between the aged-matched groups. There was a significantly greater incidence of inotrope use among the patients undergoing conventional $\mathrm{CABG}$, and their mean intubation time and weight gain were also significantly greater. The mean times in the intensive care unit were $27.4 \pm 28.7$ hours for the minimally invasive direct CABG cohort and $53.5 \pm 118.3$ hours for the conventional CABG cohort, but the medians
Table II. Postoperative data

\begin{tabular}{llll}
\hline & $\begin{array}{l}\text { MIDCAB } \\
(n=55)\end{array}$ & $\begin{array}{l}C C A B \\
(n=55)\end{array}$ & \multicolumn{1}{c}{$\mathrm{P}$} \\
\hline Mean weight gain (kg) & $2.7 \pm 3.4$ & $7.1 \pm 3.2$ & .0001 \\
Mean intubation time (h) & $4.8 \pm 12.8$ & $33.5 \pm 122.2$ & .001 \\
Median intubation time (h) & $0(0-13)$ & $10(5-33.5)$ & \\
Median ICU LOS (h) & $23(14-46)$ & $24(18-89)$ & \\
AF (No.) & 13 & 11 & .64 \\
Ventilatory failure (No.) & 2 & 2 & $\mathrm{NC}$ \\
Perioperative MI (No.) & 1 & 1 & $\mathrm{NC}$ \\
Heart failure (No.) & 1 & 1 & $\mathrm{NC}$ \\
Any ICU inotropes (No.) & 5 & 21 & .001 \\
Return for bleeding (No.) & 0 & 1 & $\mathrm{NC}$ \\
Return for revision (No.) & 5 & 1 & \\
Median hospital LOS (d) & $4(1.6-7)$ & $5(3.5-7)$ & .01 \\
\hline
\end{tabular}

Data are mean \pm standard deviation, number of patients, or median with 10th and 90th percentiles in parentheses. $M I D C A B$, Minimally invasive direct CABG; $C C A B$, conventional CABG; $I C U$, intensive care unit; $L O S$, length of stay; $N C$, not calculated (no statistical comparison performed); $M I$, myocardial infarction.

were not different to a statistically significant degree. Five of the patients in the minimally invasive direct CABG group required revision procedures in the postoperative period. These procedures ranged from graft unkinking (in 2 cases) to resection and revision of the proximal anastomosis (in 3 cases). One of these 5 patients had postoperative AF.

The mean total length of hospital stay was $5.1 \pm 1.1$ days for the patients undergoing minimally invasive direct $\mathrm{CABG}$ compared to $6.1 \pm 4.8$ days for the patients undergoing conventional $\mathrm{CABG}$, with medians of 4 and 5 days, respectively $(P=.011)$. Interestingly, the number of patients who were discharged with antidysrhythmic drugs was significantly greater among the conventional $\mathrm{CABG}$ group than among the minimally invasive direct CABG group (10 and 6, respectively, $P=.006)$.

\section{Discussion}

The incidence of $\mathrm{AF}$ after $\mathrm{CABG}$ is known to be as high as $31.9 \%$, and it is increased among cohorts with older patients. ${ }^{3}$ Our own experience with postoperative AF (noted in the Methods section) verifies these observations. Recently the problem has attracted increased attention because the resource use, specifically including length of postoperative hospital stay, is greater for patients with postoperative AF than for those without this complication. Among patients undergoing solitary CABG at our institution during the past 3 years there has been a consistent, statistically significant difference in the median length of hospital stay between patients who have postoperative $\mathrm{AF}$ and those who do not 
(1994, 7 versus $5, P=.0001 ; 1995,7$ vs $5, P=.0002$; 1996, 6 vs $5, P=.002)$.

Chauhan and colleagues ${ }^{4}$ recently reported a lower incidence of postoperative AF among patients undergoing minimally invasive direct $\mathrm{CABG}$ than among those undergoing standard CABG $(12 \%$ vs $32 \% ; P=.02)$. In their study population the mean age of the 96 patients undergoing standard CABG was greater than that of the 41 patients undergoing minimally invasive direct $\mathrm{CABG}$, but they did not find age a significant predictor of postoperative AF. Our aged-matched comparison failed to demonstrate a lower incidence of postoperative AF among those undergoing minimally invasive direct $\mathrm{CABG}$ than among those undergoing conventional CABG. Age matching did not eliminate statistically significant differences in postoperative weight gain, inotrope use, ventilator time, or total length of hospital stay.

The fact that age matching eliminated the difference in postoperative AF incidence between conventional $\mathrm{CABG}$ and minimally invasive direct $\mathrm{CABG}$ groups is the critical point of our study. The likelihood of finding no significant difference when there was one (type II error) was extremely small because the incidence of postoperative AF was actually higher in the minimally invasive direct $\mathrm{CABG}$ group than in the conventional CABG group after age matching. Indeed, knowing that the incidence of postoperative AF in our population was $34.4 \%$ before any matching (all patients during the past 10 years) and that the incidence among our minimally invasive direct $\mathrm{CABG}$ cohort was $23.6 \%$, there was a $31 \%$ difference in the incidence. If one accepts, as we certainly do, that a $30 \%$ reduction in AF is clinically significant and performs a sample size calculation for matched cohorts, with a $95 \%$ likelihood of detecting a statistically significant difference if there is one and a $95 \%$ certainty that this is not simply due to chance, one finds that the sample size required would be only 22 . We had 55 pairs. Again, the important point is that we completely eliminated the difference in the incidence of $\mathrm{AF}$ between conventional $\mathrm{CABG}$ and minimally invasive direct CABG simply by correcting for age.

The etiology of postoperative AF is not known, and many mechanisms have been suggested. These mechanisms may be divided into intraoperative or postoperative factors. Most of the attention has been focused on the postoperative period and on prophylaxis..$^{5-8}$ No one has described intraoperative mechanisms through which the incidence of postoperative AF could be reduced, but such possibilities may exist. Better myocardial (specifically atrial) preservation or cooling in patients undergoing $\mathrm{CABG}$ has not been examined in a large study. Many of the intraoperative factors that are considered as potentially influential in the incidence of postoperative AF are related to cardiopulmonary bypass, global myocardial ischemia (crossclamping), and myocardial preservation. None of these mechanisms specifically applies to patients undergoing minimally invasive direct $\mathrm{CABG}$.

Our data showed similar incidences of postoperative $\mathrm{AF}$ in the age-matched groups, so mechanisms common to both groups must be considered. The brief period of local ischemia related to transient coronary occlusion during construction of the distal anastomoses and the opening of the pericardium are 2 such factors. Although undocumented for patients undergoing minimally invasive direct $\mathrm{CABG}$, the release of endogenous catecholamines after cardiopulmonary bypass has been well documented among patients undergoing conventional $\mathrm{CABG}$, and this factor may apply to the minimally invasive direct CABG population as well. Clearly, consideration of these data can focus our efforts to reduce and manage the incidence of postoperative $\mathrm{AF}$.

\section{REFERENCES}

1. Cohn WE, Suen HC, Weintraub RM, Johnson RG. The "H" graft: an alternative approach for performing minimally invasive direct coronary artery bypass. J Thorac Cardiovasc Surg 1998;115:14851.

2. Suen HC, Johnson RG, Weintraub RM, Maslow A, Comunale ME, Cohn WE. Minimally invasive direct coronary artery bypass: our experience with 32 patients. Int J Cardiol 1997; 62:S95-100.

3. Creswell LL, Schuessler RB, Rosenbloom M, Cox JL. Hazards of postoperative atrial arrhythmias. Ann Thorac Surg 1993;56: $539-49$.

4. Chauhan VS, Gill I, Woodend KA, Tang AS. Lower incidence of atrial fibrillation after minimally invasive direct coronary artery bypass surgery (MIDCAB) than bypass surgery (CABG). Circ Abstracts 1997;1:263.

5. Laub GW, Janeira L, Muralidharan S, Riebman JB, Chen C, Neary M, et al. Prophylactic procainamide for prevention of atrial fibrillation after coronary artery bypass grafting: a prospective, double-blind, randomized, placebo-controlled pilot study. Crit Care Med 1993;21:1474-8.

6. Waldo AL, MacLean WA, Karp RB, Kouchoukos NT, James TN. Continuous rapid atrial pacing to control recurrent or sustained supraventricular tachycardias following open heart surgery. Circulation 1976;54:245-50.

7. Matloff JM, Wolfson S, Gorlin R, Harken DE. Control of postcardiac surgical tachycardias with propranolol. Circulation 1968; 37(Suppl):II133-8.

8. Daoud EG, Strickberger SA, Man KC, Goyal R, Deeb GM, Bolling SF, et al. Preoperative amiodarone as prophylaxis against atrial fibrillation after heart surgery. N Eng1 J Med 1998;337: 1785-91. 